\title{
Descemet Membrane Endothelial Keratoplasty (DMEK) in Previously Vitrectomized Eyes: Complications and Clinical Outcomes
}

\author{
Descemet-Membran-Endothel-Keratoplastik (DMEK) in zuvor \\ vitrektomierten Augen: Komplikationen und klinische Ergebnisse
}

\author{
Authors \\ Affiliation \\ Klinik für Augenheilkunde, Universitätsklinikum des \\ Saarlandes und Medizinische Fakultät der Universität des \\ Saarlandes, Homburg, Germany \\ Key words \\ DMEK, PPV, FECD, vitrectomy \\ Schlüsselwörter \\ DMEK, PPV, FECD, Vitrektomie

$\begin{array}{ll}\text { received } & 19.1 .2021 \\ \text { accepted } & 20.5 .2021 \\ \text { published online } & 26.7 .2021\end{array}$ \\ Bibliography \\ Klin Monatsbl Augenheilkd 2021; 238: 1101-1107 \\ DOI 10.1055/a-1517-4518 \\ ISSN 0023-2165 \\ (c) 2021. Thieme. All rights reserved. \\ Georg Thieme Verlag KG, Rüdigerstraße 14, \\ 70469 Stuttgart, Germany \\ Correspondence \\ Dr. Wissam Aljundi \\ Universitätsklinikum des Saarlandes und Medizinische \\ Fakultät der Universität des Saarlandes, Augenklinik \\ Kirrberger Sraße 100, 66421 Homburg, Germany \\ Phone: + 4968411622387 , Fax: + 4968411622400 \\ wissam.aljundi@uks.eu
}

Wissam Aljundi ${ }^{\mathbb{D}}$, Alaadin Abdin, Shady Suffo ${ }^{\mathbb{D}}$, Berthold Seitz ${ }^{\mathbb{D}}$, Loay Daas

\section{ABSTRACT}

Purpose To evaluate the results and complications of Descemet membrane endothelial keratoplasty (DMEK) in previously vitrectomized eyes.

Design Retrospective study of 35 eyes that had undergone DMEK, due to Fuchs endothelial corneal dystrophy (FECD), at our department with a follow-up after 6 months postoperatively. We compared the intraoperative procedure, complications, and results of DMEK between 14 previously vitrectomized pseudophakic eyes (group 1) and a control group of 21 pseudophakic non-vitrectomized eyes (group 2).
Results The unfolding time (in minutes) was significantly longer in group 1 than in group $2(10.5 \pm 6.4$ vs. $3.2 \pm 1.5$, $\mathrm{p}<0.01)$. A single re-bubbling was needed in 8 patients in group 1 (57.1\%) and in 3 patients in group 2 (14.2\%) $(p<0.01)$. Repeated re-bubbling ( $\geq 1$ time) was performed in only 5 patients of group 1 (35.7\%). There was significant postoperative improvement in best-corrected visual acuity (BCVA, in LogMAR) in both groups ( $p=0.04$ in group 1 and $p<0.01$ in group 2). The central corneal thickness (CCT, in $\mu \mathrm{m}$ ) did not differ significantly between the two groups preoperatively $(p=0.4)$ or postoperatively $(p=0.1)$. However, the CCT decreased significantly postoperatively in both groups $(p<0.01$ in both groups). The postoperative endothelial cell density $\left(E C D\right.$ in cell $\left./ \mathrm{mm}^{2}\right)$ was significantly lower in group 1 than in group $2(p=0.03)$.

Conclusion DMEK in previously vitrectomized eyes presents a surgical challenge, which requires special, and sometimes unpredictable, intraoperative maneuvers, but good functional and morphological results can be achieved. The use of the endothelial Descemet membrane lamellae (EDML) of older donors might be recommended to facilitate the intraoperative unfolding process.

\section{ZUSAMMENFASSUNG}

Ziel Evaluierung der Ergebnisse und Komplikationen der Descemet-Membran-Endothel-Keratoplastik (DMEK) in zuvor vitrektomierten Augen.

Design Retrospektive Studie von 35 Augen, die aufgrund Fuchs'scher endothelialer Hornhautdystrophie (FECD) in unserer Abteilung einer DMEK unterzogen wurden, mit einem Follow-up von mindestens 6 Monaten postoperativ.

Ergebnisse Die Entfaltungszeit (in Minuten) war in Gruppe 1 signifikant länger als in Gruppe $2(p<0,01)$. Ein einmaliges ReBubbling war bei 8 Patienten in Gruppe $1(57,1 \%)$ und bei 3 Patienten in Gruppe $2(14,2 \%)$ erforderlich $(p<0,01)$. Ein wiederholtes Re-Bubbling ( $\geq 1 \mathrm{Mal}$ ) wurde nur bei 5 Patienten der Gruppe 1 (35,7\%) durchgeführt. Postoperativ zeigte sich in beiden Gruppen eine signifikante Verbesserung der bestkorrigierten Sehschärfe (BCVA, in logMAR) ( $p=0,04$ in Gruppe 1 und $p<0,01$ in Gruppe 2). Die zentrale Hornhautdicke $(C C T$, in $\mu \mathrm{m})$ unterschied sich präoperativ $(\mathrm{p}=0,4)$ und post- 
operativ $(p=0,1)$ nicht signifikant zwischen den beiden Gruppen. Allerdings nahm die CCT postoperativ in beiden Gruppen signifikant $a b$ ( $p<0,01$ in beiden Gruppen). Die postoperative Endothelzelldichte (ECD in Zellen/ $\mathrm{mm}^{2}$ ) war in Gruppe 1 signifikant niedriger als in Gruppe $2(p=0,03)$.

Schlussfolgerung Die DMEK in zuvor vitrektomierten Augen stellt eine chirurgische Herausforderung dar, die spezielle, manchmal unvorhersehbare, intraoperative Manöver erfordert, aber es können gute funktionelle und morphologische Ergebnisse erzielt werden. Die Verwendung der endothelialen Descemet-Membran-Lamellen (EDML) älterer Spender könnte empfohlen werden, um den intraoperativen Entfaltungsprozess zu erleichtern.

\section{Introduction}

In 2006, Melles et al. described the first Descemet membrane endothelial keratoplasty (DMEK), which is one of the most frequently performed keratoplasty techniques in Germany today [1,3]. The previously prepared endothelial Descemet membrane lamellae (EDML) is introduced into the anterior chamber through a small incision and unfolded using various maneuvers [2-4]. The posterior lamellar keratoplasty leads, in suitable indications, to a shorter healing process, faster rehabilitation of visual acuity, and better postoperative astigmatism compared to penetrating keratoplasty [5-8]. An intact iris-lens diaphragm and the support of vitreous pressure are essential for good control of the anterior chamber depth and to avoid a complicated graft unfolding process [9]. For this reason, the use of DMEK in previously vitrectomized eyes was avoided or at least only performed by experienced surgeons using difficult maneuvers [10]. This is due to the lack of pressure in the posterior chamber as well as the deeper anterior chamber.

The purpose of this study was to investigate whether the benefits of DMEK in previously vitrectomized eyes with Fuchs endothelial corneal dystrophy (FECD) can be maintained despite the intraoperative challenges.

\section{Patients and Methods}

\section{Participants}

We retrospectively analyzed the data of patients with FECD who underwent DMEK in our department with a mean follow-up time of at least 6 months. This study included 14 previously vitrectomized pseudophakic eyes of 14 patients [ 8 men, 6 women (group 1)] and 21 pseudophakic non-vitrectomized eyes of 21 patients [9 men, 12 women (control group, group 2)]. The DMEK was performed by three experienced surgeons using the same technique in both groups. The age of the patients, the preoperative bestcorrected visual acuity (BCVA, in LogMAR), and the preoperative central corneal thickness (CCT, measured in Pentacam Oculus $\mathrm{GmbH}$, Wetzlar, Germany, in $\mu \mathrm{m}$ ) did not significantly differ between the two groups.

\section{The preoperative parameters}

The preoperatively analyzed data included CCT, BCVA, and anterior chamber depth (ACD, measured in Pentacam Oculus $\mathrm{GmbH}$, Wetzlar, Germany, in millimeters), as well as the cause of vitrectomy in group 1.

\section{The surgical technique}

A detailed description of our DMEK technique "step-by-step" can be found in our previous publications (https://doi.org/10.1007/ s00347-020-01134-1, https://doi.org/10.1002/ca.22900) [11, 12].

An $8.0 \mathrm{~mm}$ ring-shaped marker was placed on the central corneal surface of the patient. After completing the descemetorhexis, a Descemet membrane stripping with an inverted hook (Price Endothelial Keratoplasty Hook; Moria SA) was performed in the area of this marking under air. Using a small spatula, the rolled prepared EDML could be guided into the large opening of the glass cartridge. A small curved cannula was used to fill the tip of the glass cartridge with the dark blue dye DORC MEMBRANEBLUE DUAL (DORC,VN Zuidland, Netherlands) until the whole roll was completely covered with the deep blue dye. Then, the air used during the descemetorhexis was completely removed from the anterior chamber, which was filled afterwards with balanced salt solution (BSS) in preparation for the injection of the EDML. After injecting the EDML together with the blue dye into the anterior chamber by pressing the plunger, the blue dye was completely flushed out of the anterior chamber by using a Sautter cannula and BSS. A small air bubble from an insulin syringe was inserted into the inner lumen of the rolled EDML in the eyes of group 1 ( $\bullet$ Fig. 1). By appropriately tapping on the cornea, the air bubble rolling towards the periphery was used to open the edges of the EDML sequentially. Afterwards the small air bubble was enlarged to complete the unfolding of the EDML. To further facilitate the unfolding process, the anterior chamber was shallowed using active suction of aqueous humor and BSS through the paracentesis. After that, the air bubble was carefully and completely aspirated by using a Sautter cannula. By doing this, the cornea typically collapses and the EDML remains on the iris - even in a deep anterior chamber after vitrectomy. The cannula was removed without affecting the position of the EDML. A cannula connected to a $20 \%$ SF6 (sulfur hexafluoride) gas-filled syringe was then advanced under the EDML towards the center of the pupil. Through controlled gas injection, the EDML was attached to the back of the host cornea $[13,14]$.

\section{The intraoperative parameters}

The surgeon and the surgical team must fill in a protocol with the following information after each completed DMEK at our department: the total duration of the operation in minutes, the unfolding time (the time from the complete insertion of the EDML into the anterior chamber until the SF6 gas injection, in minutes), the surgical grade of difficulty as well as donor information. The surgical grade of difficulty is subjectively classified by the surgeon in 


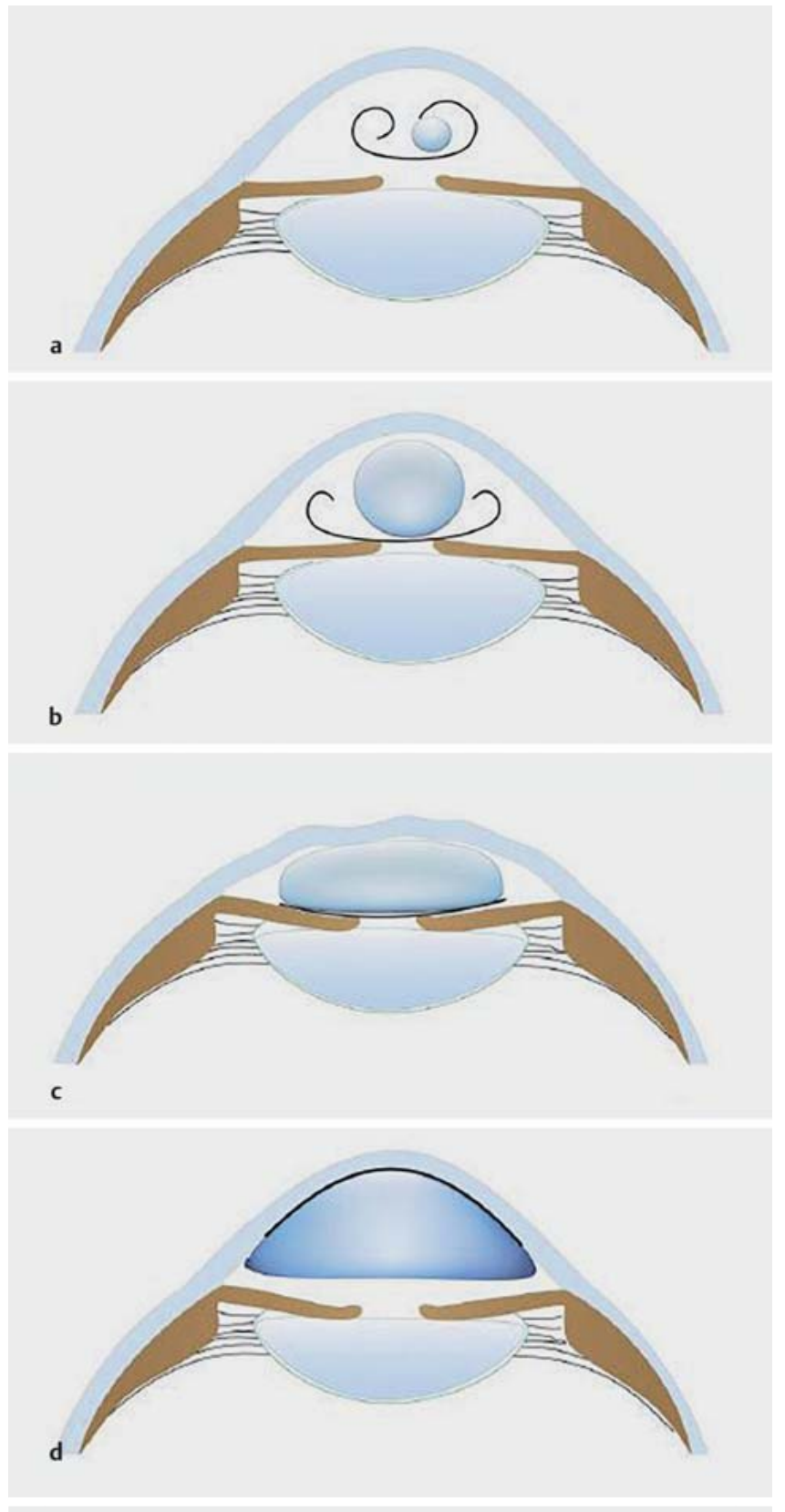

- Fig. 1 An intraoperative illustration showing the use of an air bubble above the endothelial Descemet membrane lamellae (EDML) to facilitate the unfolding of the EDML in previously vitrectomized eyes (G1). a A small air bubble was injected into the inner lumen of the rolled EDML. $b$ Partial unfolding of the EDML after the air bubble was enlarged and moved toward the periphery with tapping the cornea to unfold the edges of the EDML. c The unfolding of the EDML was completed after the anterior chamber was shallowed by actively aspirating aqueous humor and BSS through paracentesis, whereby the cornea typically collapses. $\mathbf{d}$ The final position of the EDML attached to the cornea after removing the air bubble and injection of $20 \%$ sulfur hexafluoride (SF6) under the EDML.

5 grades: 0 for a mild DMEK to 4 for an extremely complicated DMEK. Both donor age and endothelial cell density (ECD, cell/ $\mathrm{mm}^{2}$ ) are documented under donor information. The intraopera- tive parameters were collected and analyzed based on these protocols.

\section{The postoperative inpatient care}

The intraocular pressure of the operated eye was measured and recorded every 2 hours for the first 12 hours postoperatively. The graft attachment was checked daily using anterior segment optical coherence tomography (CASIA 2, Tomey Corporation, Nagoya, Japan) and a re-bubbling was performed in case of graft dehiscence. All patients received a standardized local or systemic therapy and were regularly examined on the slit lamp.

\section{The postoperative parameters}

We examined the functional results of DMEK after 6 months postoperatively (BCVA in LogMAR, CCT in $\mu \mathrm{m}$, ECD in cell $/ \mathrm{mm}^{2}$ ), as well as postoperative complications.

\section{The statistical analysis}

The data was collected with Microsoft Excel 2010 (Microsoft Corporation, Redmond, WA, USA) and analyzed with SPSS version 26 (SPSS Inc., Chicago, IL, USA). In order to compare the values, we used the Mann-Whitney $U$ test, and statistical significance was defined as $p \leq 0.05$.

\section{Main limitations of this study}

The main potential limitations of our study were the retrospective nature of the work, a relatively small population from a single medical center, and the use of decimal visual acuity as opposed to ETDRS vision charts. However, to obtain more reliable values to describe BCVA, decimal values were converted to LogMAR equivalents before running the statistics.

\section{Results}

\section{Preoperative}

The mean age of the patients was $73 \pm 10$ years in group 1 and $76 \pm 5$ years in group $2(p=0.39)$. The CCT was $640 \pm 65 \mu \mathrm{m}$ in group 1 and $648 \pm 63 \mu \mathrm{m}$ in group $2(p=0.4)$. BCVA (in LogMAR) was $0.7 \pm 0.4$ in group 1 compared to $0.5 \pm 0.2$ in group 2 $(p=0.62)$. The anterior chamber depth (in millimeters) was $4.2 \pm 0.5 \mathrm{~mm}$ in group 1 and $3.7 \pm 0.7 \mathrm{~mm}$ in group $2(p=0.04)$. The cause of the previously performed vitrectomy in group 1 was an epiretinal membrane in 3 patients (21\%) and a retinal detachment in 11 patients (79\%). Both donor age and the endothelial cell density of the EDML (ECD, in cell/ $\mathrm{mm}^{2}$ ) did not differ significantly between the two groups. The donor age was $73 \pm 11$ years in group 1 and $77 \pm 8$ years in group $2(p=0.28)$. ECD was $2621 \pm$ $314 \mathrm{cell} / \mathrm{mm}^{2}$ in group 1 and $2535 \pm 236 \mathrm{cell} / \mathrm{mm}^{2}$ in group 2 $(p=0.61)$.

\section{Intraoperative}

The total surgery time (in minutes) was significantly longer in group 1 (40 $\pm 18 \mathrm{~min})$ than in group $2(28 \pm 11 \mathrm{~min})(p=0.01)$. The graft unfolding time (in minutes) was significantly longer in group 1 (10.5 $\pm 6.4 \mathrm{~min})$ compared to group 2 (3.2 $\pm 1.5 \mathrm{~min})$ $(p<0.01)$. The surgical grade of difficulty of the DMEK in group 1 


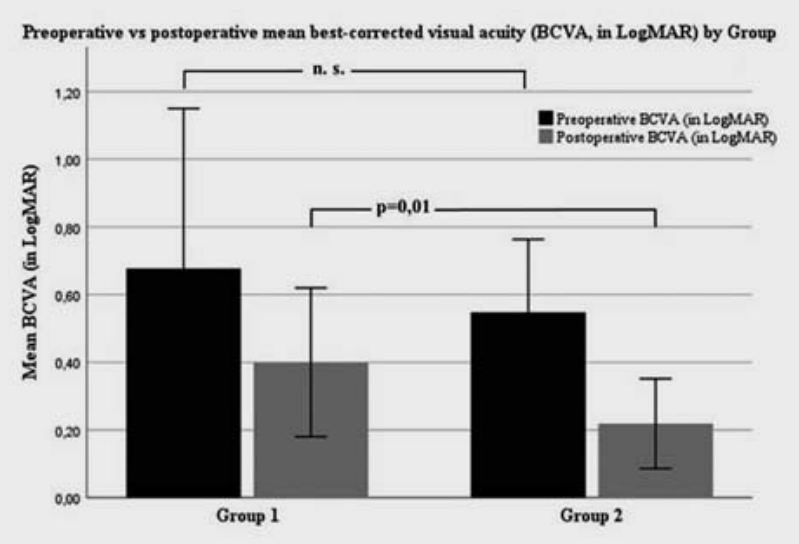

- Fig. 2 Comparison of preoperative and postoperative best-corrected visual acuity (BCVA, in LogMAR) in the same group: significantly better in group $1\left({ }^{*} \mathrm{p}=0.04\right)$ and in group $2\left({ }^{*} \mathrm{p}<0.01\right)$. Comparison of preoperative BCVA (not significant, n. s., $p=0.62$ ) and postoperative BCVA $(p=0.01)$ between the two groups.

was classified as mild (grade 0 ) in only one patient (7\%), otherwise it was moderate (grade 1 ) in one patient (7\%), difficult (grade 2 ) in 3 patients (22\%), very difficult (grade 3 ) in 6 patients (42\%), and extremely difficult (grade 4 ) in 3 patients (22\%). On the other hand, the surgical grade of difficulty of the DMEK in group 2 was classified as mild (grade 0 ) in 19 patients $(90 \%)$, moderate (grade $1)$ in one patient ( $5 \%)$, and difficult in one patient $(5 \%)(p<0.01)$.

\section{Postoperative}

The maximum intraocular pressure measured during the first 12 postoperative hours (in $\mathrm{mmHg}$ ) was significantly higher in group $1(23 \pm 10 \mathrm{mmHg})$ in comparison to group $2(16 \pm 6 \mathrm{mmHg})$ $(p=0.01)$. A single re-bubbling due to graft detachment was performed in 8 eyes in group 1 (57.1\%), which was necessary in only 3 eyes in group $2(14.2 \%)(p<0.01)$.

Interestingly, the graft detachment, which had led to this rebubbling, occurred earlier in group 1 compared to group 2. In group 1, it occurred within the first 5 postoperative days in 7 eyes (87\%) and after 12 days in 1 eye (13\%) of the previously mentioned 8 eyes. In group 2, graft detachment occurred between the 14th and the 16th postoperative day in all 3 eyes. Furthermore, it was found that a repeated re-bubbling ( $\geq 1$ time) was indicated in only 5 patients (35.7\%) of group 1 .

The mean follow-up was $6.1 \pm 0.8$ months and $6.3 \pm 0.4$ months in group 1 and group 2 , respectively $(p=0.43)$. The postoperative BCVA (in LogMAR) increased significantly in both groups, from $0.7 \pm 0.4$ to $0.4 \pm 0.2(p=0.04)$ in group 1 and from $0.5 \pm 0.2$ to $0.2 \pm 0.1(p<0.01)$ in group 2 . The postoperative BCVA in group 2 was significantly higher than in group 1 $(p=0.01)$. Interestingly, the visual improvement (delta BCVA, calculated by subtracting the postoperative BCVA from the preoperative BCVA for each patient) did not differ significantly between the two groups $(p=0.07)(\triangleright$ Fig. 2 ).

Postoperatively, the CCT (in $\mu \mathrm{m}$ ) decreased significantly in both groups, from $640 \pm 65 \mu \mathrm{m}$ to $569 \pm 89 \mu \mathrm{m}$ in group 1

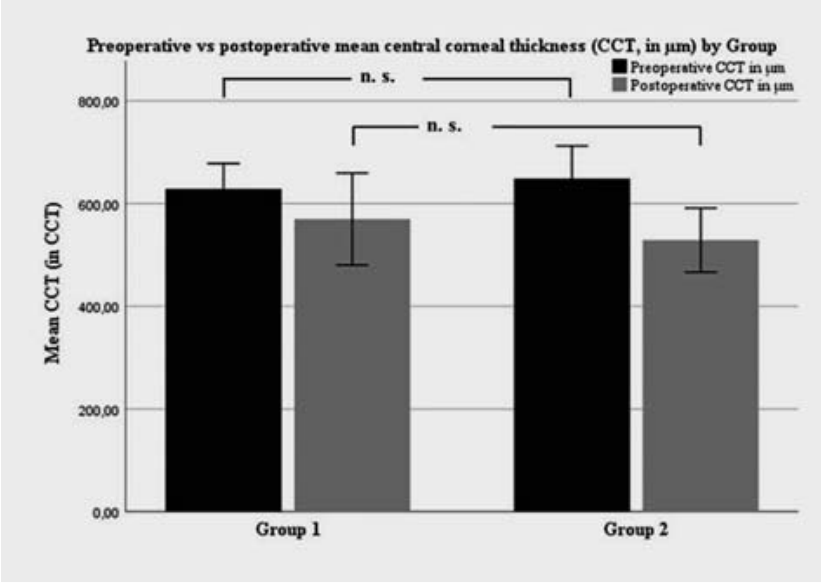

- Fig. 3 Comparison of preoperative and postoperative central corneal thickness (CCT, in $\mu \mathrm{m})$ in the same group: significantly better in group $1\left({ }^{*} \mathrm{p}<0.01\right)$ and in group $2\left({ }^{* *} \mathrm{p}<0.01\right)$. Comparison of preoperative CCT (not significant, n. s., $\mathrm{p}=0.4$ ) and postoperative CCT $(p=0.1)$ between the two groups.



- Fig. 4 Comparison of endothelial cell density (ECD, in $\mu \mathrm{m})$ of the endothelial Descemet membrane lamellae (EDML) and the postoperative ECD in the same group: significantly lower in group 1 $\left({ }^{*} \mathrm{p}<0.01\right)$ and in group $2\left({ }^{*} \mathrm{p}<0.01\right)$. Comparison of ECD of the EDML preoperatively (not significant, n.s., $p=0.61$ ) and the postoperative ECD $(p=0.03)$ between the two groups.

$(p<0.01)$ and from $648 \pm 63 \mu \mathrm{m}$ to $528 \pm 62 \mu \mathrm{m}$ in group 2 $(p<0.01)$. However, the postoperative CCT did not differ significantly between the two groups ( $p=0.1)$ ( $\triangleright$ Fig. 3 ).

The postoperative ECD (in cell/ $\mathrm{mm}^{2}$ ) was significantly lower than the preoperative ECD of the EDML in group $1(2621 \pm 314$ vs. $1478 \pm 550, p<0.01)$, as well as in group $2(2535 \pm 236$ vs. $1889 \pm 291, p<0.01)$. In group 1 , the postoperative ECD was significantly lower than in group $2(p=0.03)$ ( $\triangleright$ Fig. 4$)$.

A summary of our results is shown in $>$ Table 1. 
- Table 1 A summary of our results.

\begin{tabular}{|c|c|c|c|}
\hline & G1 & G2 & $\mathbf{p}$ \\
\hline Number of eyes & 14 & 21 & \\
\hline Gender (male vs. female) & 8 vs. 6 & 9 vs. 12 & 0.56 \\
\hline Age & $73 \pm 10$ & $76 \pm 5$ & 0.39 \\
\hline Preoperative BCVA (in LogMAR) & $0.7 \pm 0.4$ & $0.5 \pm 0.2$ & 0.62 \\
\hline Preoperative CCT (in $\mu \mathrm{m}$ ) & $640 \pm 65$ & $648 \pm 63$ & 0.41 \\
\hline Preoperative ACD (in mm) & $4.2 \pm 0.5$ & $3.7 \pm 0.7$ & 0.04 \\
\hline Age of the donor (in years) & $73 \pm 11$ & $77 \pm 8.5$ & 0.28 \\
\hline $\mathrm{ECD}$ of the EDML (in cell/mm²) & $2621 \pm 314$ & $2535 \pm 236$ & 0.61 \\
\hline Unfolding time (in minutes) & $10.5 \pm 6.4$ & $3.2 \pm 1.5$ & $<0.01$ \\
\hline Operation duration (in minutes) & $40.3 \pm 18.3$ & $28.3 \pm 11.6$ & 0.01 \\
\hline Maximum IOP (in mmHg) & $23 \pm 10$ & $16.7 \pm 6$ & 0.01 \\
\hline Follow-up time (in months) & $6.1 \pm 0.8$ & $6.3 \pm 0.4$ & 0.43 \\
\hline Postoperative BCVA (in LogMAR) & $0.4 \pm 0.2$ & $0.2 \pm 0.1$ & 0.01 \\
\hline Postoperative CCT (in $\mu \mathrm{m}$ ) & $569 \pm 89$ & $528 \pm 62$ & 0.14 \\
\hline Postoperative ECD (in cell/mm²) & $1478 \pm 550$ & $1889 \pm 291$ & 0.03 \\
\hline \multirow[t]{2}{*}{ Single re-bubbling rate } & $57.1 \%$ & $14.2 \%$ & $<0.01$ \\
\hline & Preoperatively & Postoperatively & $\mathbf{p}$ \\
\hline BCVA (in LogMAR) in group 1 & $0.7 \pm 0.4$ & $0.4 \pm 0.2$ & 0.04 \\
\hline BCVA (in LogMAR) in group 2 & $0.5 \pm 0.2$ & $0.2 \pm 0.1$ & $<0.01$ \\
\hline $\mathrm{CCT}$ (in $\mu \mathrm{m}$ ) in group 1 & $640 \pm 65$ & $569 \pm 89$ & $<0.01$ \\
\hline CCT (in $\mu \mathrm{m}$ ) in group 2 & $648 \pm 63$ & $528 \pm 62$ & $<0.01$ \\
\hline $\mathrm{ECD}$ (in cell/mm²) in group 1 & $2621 \pm 314$ & $1478 \pm 550$ & $<0.01$ \\
\hline $\mathrm{ECD}$ (in cell $/ \mathrm{mm}^{2}$ ) in group 2 & $2535 \pm 236$ & $1889 \pm 291$ & $<0.01$ \\
\hline
\end{tabular}

\section{Discussion}

Due to its complicated and potentially "surprising" intraoperative procedure, DMEK in previously vitrectomized eyes has been studied several times. The unfolding process of the EDML is still challenging without a standardized operative procedure. In previously vitrectomized eyes, the posterior support of the vitreous body is missing, resulting in an unstable iris-lens diaphragm and, therefore, the anterior chamber becomes very deep during surgery [9].

In 2015, Yoeruek et al. found that DMEK was apparently successful in restoring visual acuity even in 20 previously vitrectomized eyes, based on the results obtained approximately 1 year after surgery. BCVA (in LogMAR) increased significantly from $1.4 \pm 0.5$ to $0.6 \pm 0.3$ despite previous retinal comorbidities. Nevertheless, the total intraoperative complication rate was higher in comparison to a "normal" DMEK. Immediate intraoperative corrective measures, mainly due to renewed graft curl or globe collapse, were required in 13 out of 20 eyes. These measures were quite difficult in some cases. Also, the unfolding process required a longer period of time. In addition, unpredictable maneuvers had to be performed in the anterior chamber. Interestingly, it was discussed in the same study that EDML from older donors curl up less and therefore unfold more easily intraoperatively. For this reason, these EDMLs might be preferred in eyes that were previously vitrectomized. Reasons for this fact are the age-related decrease in elastin levels, changes in collagen composition, or the increase in non-enzymatic glycosylation, which increases the rigidity of the Descemet membrane [15].

In 2014, Heinzelmann et al. examined the influence of donor characteristics on the intra- and postoperative results of DMEK. In that study, it was found that the unfolding process took longer when EDML from younger donors was used and that EDML from older donors with a higher ECD (e.g., over 65 years of age with ECD of more than 2300 cells $/ \mathrm{mm}^{2}$ ) was more suitable for both the inexperienced DMEK surgeons and the complex cases [16]. Based on experience, we agree with this consideration, but the necessary guidelines to organize this issue are still missing. Fur- 
thermore, many surgical techniques and methods have been developed to facilitate this process or to replace the lack of posterior chamber pressure. One of these methods was the intraoperative use of a pars plana infusion. In 2017, Sorkin et al. reported the first results of the use of this infusion 6 months postoperatively, which looked promising as it led to a more stable anterior chamber and an easier unfolding process [9]. However, in 2020, Mednick et al. found that this use may have increased the risk of retinal complications after 2 years in 5 of the 15 eyes studied. Two patients developed retinal detachment, two patients developed cystoid macular edema, and one patient developed macular schisis. According to this, Descemet stripping automated endothelial keratoplasty (DSAEK) may be the preferred technique in these demanding vitrectomized eyes [17].

A study in 2018 by Yoeruek and Bartz-Schmidt found that the intraoperative temporary implantation of a hydrophilic methacrylate plate of $12.8 \mathrm{~mm}$ in size led to a more stable anterior chamber and better graft control and thus to better results in seven previously vitrectomized eyes. Its use allows the creation of a double anterior chamber and a stable globe without the risk of a globe collapse [18]. This could be helpful in vitrectomized eyes, but sufficient experience is needed, especially in explanting the plate to guarantee the necessary protection of the endothelial cells. Similar to our technique, but with a second bubble below the EDML, Hayashi and Kobayashi developed the "double bubble" technique from the well-known Dapena technique in a case series of six previously vitrectomized eyes $[19,20]$. Similar to our results, the unfolding time with the double-bubble technique was about 10 minutes, and the postoperative BCVA, CCT, and ECD results were acceptable [20]. In our study, the EDML was unfolded by using an additional air bubble and tapping on the corneal epithelium. In addition, the anterior chamber was flattened by active suction of the aqueous humor for better control of the EDML. In this context, it is important to emphasize that the three semi-circular markings at the edge of the EDML during its preparation played a major intraoperative role, especially in such complex cases with an exceptionally deep anterior chamber [14].

In this study, we used sulfur hexafluoride diluted with $80 \%$ room air (SF6 20\%, EasyGas SF6, Fluoron GmbH, Ulm, Germany) to achieve the maximum non-expansive concentration. The halflife of SF6 is 2.5 days, and the intraocular residence time is approximately 12 days. The absence of SF6 gas endothelial toxicity compared to other long-acting gas formulations (e.g., Perfluoropropane C3F8 12\%), which are normally used in retinal surgery, has been studied in the literature [21-23] and represents the main benefit of using this type of gas. To determine whether such long-acting gas formulations could help to reduce the increased rate of re-bubbling in such complicated eyes, large clinical prospective studies are still lacking.

Our results were satisfying regarding BCVA and CCT despite the intraoperative challenges. DMEK in both groups had led to a significantly better BCVA, and a significantly decreased CCT compared to the preoperative BCVA and CCT in the same group. It is true that the postoperative BCVA in group 2 was significantly better than in group 1, but this can be explained by the retinal comorbidities of the eyes in group 1, especially since the delta BCVA after DMEK did not differ significantly between the two groups.
On the other hand, DMEK in group 1 had led to a significantly longer unfolding time and a significantly higher re-bubbling rate compared to group 2, which may have led to the significantly decreased postoperative ECD in group 1 compared to group 2 .

It has been proposed that DSAEK has advantages over DMEK for endothelial decompensation after vitrectomy [24]. Since the DSAEK graft does not scroll, it is easier to attach it to the host cornea than the $20 \mu \mathrm{m}$ DMEK graft. In addition, the potentially reduced visual acuity after DSAEK is supposed to be acceptable in view of the anyway limited visual acuity due to the macular compromise after vitrectomy.

In contrast, the previously vitrectomized eyes have been seen in the literature as "not good candidates" for DSAEK. The reason for this is that the endothelial lenticules could fall into the vitreous cavity during the surgery or early on the postoperative day [25].

The intraocular pressure after DMEK, especially in vitrectomized eyes, should be monitored regularly and in short intervals during the first postoperative hours to detect pupillary block glaucoma and should be treated if necessary. In such cases, it could happen more easily that a gas bubble may hide behind the iris due to the deeper anterior chamber and missing vitreous body.

In conclusion, DMEK seems to be a feasible option to improve visual acuity in endothelial pathologies, even in previously vitrectomized eyes. However, the unfolding process tends to be more complicated compared to a "normal” DMEK. Larger studies are necessary to further improve the intraoperative techniques of DMEK in vitrectomized eyes or to determine whether DSAEK might be the preferred method in complicated vitrectomized eyes.

\section{Acknowledgements}

We thank Ms. Christina Turner for her linguistic support in editing our manuscript. We thank Mr. Ashkan Amir for his technical support in illustration processing. We also thank Mrs. Ute Vogelgesang, as well as the entire staff of the Klaus Faber Center for Corneal Diseases incl. LIONSCornea Bank Saar-Lor-Lux, Trier/Westpfalz, for their support in collecting important intraoperative data.

\section{Conflict of Interest}

The authors declare that they have no conflict of interest.

\section{References}

[1] Daniel MC, Böhringer D, Lapp T et al. Die Keratoplastik in Deutschland: systematische Auswertung der Krankenhausqualitätsberichte der Jahre 2006 bis 2017. Klin Monbl Augenheilkd 2021; 238: 288-292

[2] Guerra FP, Anshu A, Price MO et al. Descemet's membrane endothelial keratoplasty: prospective study of 1-year visual outcomes, graft survival, and endothelial cell loss. Ophthalmology 2011; 118: 2368-2373

[3] Melles GRJ, San Ong T, Ververs B et al. Descemet membrane endothelial keratoplasty (DMEK). Cornea 2006; 25: 987-990

[4] Price FW jr., Price MO. Descemet's stripping with endothelial keratoplasty in 200 eyes: early challenges and techniques to enhance donor adherence. J Cataract Refract Surg 2006; 32: 411-418

[5] Asi F, Daas L, Milioti G et al. Triple Descemet membrane endothelial keratoplasty for Haab striae with endothelial decompensation in congenital glaucoma. JCRS Online Cas Rep 2019; 7: 38-41 
[6] Allan BDS, Terry MA, Price FW jr. et al. Corneal transplant rejection rate and severity after endothelial keratoplasty. Cornea 2007; 26: 10391042

[7] Hos D, Tuac O, Schaub F et al. Incidence and clinical course of immune reactions after Descemet membrane endothelial keratoplasty: retrospective analysis of 1000 consecutive eyes. Ophthalmology 2017; 124 : 512-518

[8] Steven P, Hos D, Heindl LM et al. Immune reactions after DMEK, DSAEK and DALK. Klin Monbl Augenheilkd 2013; 230: 494-499

[9] Sorkin N, Einan-Lifshitz A, Ashkenazy Z et al. Enhancing Descemet Membrane Endothelial Keratoplasty in Postvitrectomy Eyes With the Use of Pars Plana Infusion. Cornea 2017; 36: 280-283

[10] Saad A, Awwad ST, El Salloukh NA et al. C-Press Technique to Facilitate Descemet Membrane Endothelial Keratoplasty Surgery in Vitrectomized Patients: A Case Series. Cornea 2019; 38: 1198-1201

[11] Seitz B, Daas L, Bischoff-Jung M et al. Anatomy-based DMEK Wetlab in Homburg/Saar: Novel aspects of donor preparation and host maneuvers to teach descemet membrane endothelial keratoplasty. Clin Anat 2018; 31: $16-27$

[12] 12

Seitz B, Daas L, Flockerzi E et al. [Descemet membrane endothelial keratoplasty DMEK - Donor and recipient step by step]. Ophthalmologe 2020; 117: 811-828

[13] Abdin A, Daas L, Pattmöller M et al. Negative impact of dextran in organ culture media for pre-stripped tissue preservation on DMEK (Descemet membrane endothelial keratoplasty) outcome. Graefes Arch Clin Exp Ophthalmol 2018; 256: 2135-2142

[14] Bachmann BO, Laaser K, Cursiefen C et al. A method to confirm correct orientation of descemet membrane during descemet membrane endothelial keratoplasty. Am J Ophthalmol 2010; 149: 922-925

[15] Yoeruek E, Rubino G, Bayyoud T et al. Descemet membrane endothelial keratoplasty in vitrectomized eyes: clinical results. Cornea 2015; 34: 1-5
[16] Heinzelmann S, Hüther S, Böhringer D et al. Influence of donor characteristics on descemet membrane endothelial keratoplasty. Cornea 2014; 33: 644-648

[17] Mednick Z, Sorkin N, Einan-Lifshitz A et al. Long-Term Outcomes of Descemet Membrane Endothelial Keratoplasty in Postvitrectomized Eyes With the Use of Pars Plana Infusion. Cornea 2020; 39: 457-460

[18] Yoeruek E, Bartz-Schmidt KU. Novel Technique for Improving Graft Unfolding in Vitrectomized Eyes Using a Temporary Diaphragm in Descemet Membrane Endothelial Keratoplasty. Cornea 2018; 37: 1334 1336

[19] Tong CM, Gerber-Hollbach N, Nieves JP et al. "No-touch” DMEK surgical technique. Pan Am J Ophthalmol 2015; 14: 72-76

[20] Hayashi T, Kobayashi A. Double-bubble technique in Descemet membrane endothelial keratoplasty for vitrectomized eyes: a case series. Cornea 2018; 37: 1185-1188

[21] Schaub F, Enders P, Snijders K et al. One-year outcome after Descemet membrane endothelial keratoplasty (DMEK) comparing sulfur hexafluoride (SF6) $20 \%$ versus $100 \%$ air for anterior chamber tamponade. Br J Ophthalmol 2017; 101: 902-908

[22] Hesse M, Kuerten D, Walter P et al. The effect of air, SF6 and C3F8 on immortalized human corneal endothelial cells. Acta Ophthalmol 2017; 95: e284

[23] Schaub F, Simons HG, Roters S et al. Einfluss von 20\% Schwefelhexafluorid (SF6) auf humane korneale Endothelzellen. Ophthalmologe 2016; 113: $52-57$

[24] Tsatsos M, Liarakos VS, MacGregor C et al. Endothelial keratoplasty: is Descemet membrane endothelial keratoplasty the Holy Grail of lamellar surgery? No. Eye (Lond) 2017; 31: 1333-1336

[25] Eguchi H, Miyamoto T, Hotta F et al. Descemet-stripping automated endothelial keratoplasty for vitrectomized cases with traumatic aniridia and aphakic bullous keratopathy. Clin Ophthalmol 2012; 6: 1513-1518 